\title{
Spastic paraplegia-Paget disease of bone syndrome
}

INSERM

\section{Source}

INSERM. (1999). Orphanet: an online rare disease and orphan drug data base. Spastic paraplegia-Paget disease of bone syndrome. ORPHA:329475

Spastic paraplegia-Paget disease of bone syndrome is an extremely rare, complex form of hereditary spastic paraplegia characterized by a slowly progressive spastic paraplegia (with increased muscle tone, decreased strength in the anterior tibial muscles and hyperreflexia in the lower extremities with Babinski sign) presenting in adulthood, associated with Paget disease of the bone. Cognitive decline, dementia and myopathic changes at muscle biopsy have not been reported. 